\title{
GRÁVIDA PERFEITA: EFEITOS DO DISCURSO MIDIÁTICO DA BOA FORMA VOLTADO PARA GESTANTES
}

\section{PERFECT PREGNANCY: THE EFFECTS OF BEING IN GOOD SHAPE MEDIA DISCOURSES FOR PREGNANT WOMEN}

\author{
Rodrigo Daniel SANCHES ${ }^{1}$, Lucília Maria Abrahão e SOUSA ${ }^{2}$
}

\section{Resumo:}

Esse trabalho busca investigar e refletir, na perspectiva teórica da Análise do Discurso (Pêcheux; Orlandi), em interface com pesquisadores das Ciências Sociais, os efeitos de sentido produzidos pelo discurso midiático da boa forma voltado para gestantes. O corpus da pesquisa é composto por revistas e sites de boa forma e dietas. A nossa hipótese é a de que esse discurso midiático faz circular efeitos de sentidos que acabam por ditar como a mulher contemporânea deve se comportar em relação ao seu corpo, mesmo diante de uma circunstância biológica como a gravidez. O sujeito-leitor é incitado a desejar um corpo perfeito, já que uma vida perfeita se materializa em um corpo igualmente perfeito.

Palavra-chave: Discurso; Corpo; Mulher; Mídia; Gravidez

\begin{abstract}
:
The present research seeks to investigate and reflect (at the interface of the theoretical perspective of Discourse Analysis - Pêcheux; Orlandi - and the Social Sciences) on the effects of sense produced by the mediatic discourse of good shape directed to pregnant women. The research corpus is composed of magazines and websites of good shape and diets. Our hypothesis is that this mediatic discourse circulates effects of meanings that end up dictating how contemporary women should behave in relation to their bodies, even in the face of a biological condition such as pregnancy. The subject-reader is urged to desire a perfect body, since a perfect life materializes in an equally perfect body.
\end{abstract}

Keywords: Discourse, Body; Women; Media; Pregnancy

\footnotetext{
${ }^{1}$ Doutor em Psicologia pela Faculdade de Filosofia, Ciências e Letras de Ribeirão Preto da Universidade de São Paulo (FFCLRP/USP), mestre em Comunicação e Semiótica (PUC/SP) e graduado em Comunicação Social - Publicidade e Propaganda (Centro Universitário Ibero-Americano). Email: rodrigo.dsa@gmail.com

${ }^{2}$ Docente com dedicação exclusiva da Universidade de São Paulo e bolsista de Produtividade 2 do CNPq. Doutorado direto em Psicologia pela Faculdade de Filosofia, Ciências e Letras de Ribeirão Preto da Universidade de São Paulo. Livre Docência em Ciência da Informação pela mesma instituição. Email: luciliamasousa@gmail.com
} 


\section{Introdução: o texto midiático das dietas e "boa forma"}

Ao refletir sobre a relação íntima e estreita entre linguagem, sujeitos e sociedade, Payer (2005) aponta que a contemporaneidade oferece muitas questões que nos incomodam, e cabe a cada um de nós tentar identificar e prover de sentidos em alguma direção que valha a pena. No presente artigo, apontaremos para uma direção específica: investigar e refletir sobre os efeitos de sentidos do discurso midiático da "boa forma" voltado para as gestantes, que fornece uma série de artifícios para a mulher manter o corpo magro/em forma antes, durante e após a gravidez.

Com base nos referenciais teórico-metodológicos da Análise do Discurso (AD), de matriz franco-brasileira, em especial os conceitos de forma-sujeito e formação discursiva, buscamos analisar a questão da boa forma na gravidez através da relação entre o sujeito-mulher, a mídia (o texto da mídia) e o mercado. Os resultados deste artigo apontam que o discurso midiático da boa forma direcionado à gestante acaba por ditar como a mulher contemporânea deve se comportar em relação ao seu corpo mesmo diante de um evento biológico e cultural como a gravidez, incentivando a busca de um formato corporal idealizado e, muitas vezes, incompatível com o período gestacional.

O corpus $^{3}$ selecionado para este artigo é composto por recortes textuais dos seguintes periódicos e sites:

Publicações impressas:

1. Dieta Já;

2. Boa Forma;

3. Corpo a Corpo;

4. Shape Brasil ${ }^{4}$;

5. Women's Health.

\footnotetext{
${ }^{3} \mathrm{O}$ corpus deste artigo faz parte de uma pesquisa de Doutorado, maior e mais abrangente, que investiga a relação entre o sujeito, o corpo e o discurso midiático das novas dietas e suas supostas novidades.

${ }^{4}$ A coleta da revista Shape Brasil correu até maio de 2018, quando sua circulação foi interrompida (edição n. 69). Decidimos manter o periódico em nosso corpus por se tratar de uma importante e interessante amostra do discurso das dietas.
} 


\section{míDiA

Sites:

6. corpoacorpo.uol.com.br;

7. mdemulher.abril.com.br.

A escolha dos periódicos teve como base três fatores: a abordagem das dietas para o público feminino e suas novidades; o tempo de permanência no mercado e, além da publicação impressa, dispor de versão on-line com espaço para comentário dos leitores e internautas. A coleta do material para análise foi realizada da seguinte forma: 1 . edições impressas: de janeiro de 2014 a dezembro de 2017, mensalmente ou de acordo com a periodicidade de cada publicação; 2. versões digitais: de janeiro a dezembro de 2017; 3. selecionamos os discursos midiáticos (materialidade significante) e os comentários dos leitores e sujeitos-internautas que façam referência às dietas e exercícios para as gestantes.

Este artigo será dividido em cinco partes: 1. a noção de corpo; 2. conceituação de formação discursiva, uma breve história da cintura e a noção de geometrização; 3. A noção de mercado, conceituação de forma-sujeito e análise da grávida-perfeita; 4. análise do discurso das "celebridades-grávidas"; 5. considerações finais. Para entender o fenômeno midiático da boa forma durante o processo gestacional, questionamos: qual a relação da mulher com o seu corpo na atualidade? No caso específico, qual a relação do corpo com a formação discursiva das dietas e da boa forma voltadas para gestantes? A relação entre a mídia e o corpo nos dias atuais está intimamente atrelada a um processo de "construção do corpo". Neste processo de formatação do corpo coetâneo, "nos interessa o discurso produzido pela mídia e materializado em práticas sociais e condutas corporais" (BENEDETTI; ROMÃO, 2007, s/p), como, por exemplo, o ato de emagrecer através das dietas sugeridas pela mídia.

O corpo é o lugar no qual se inscrevem/escrevem leis sociais por meio de práticas e discursos. Ele é o resultado de um discurso sócio-cultural e histórico. "Sendo a linguagem uma forma de ação e prática social, o corpo se faz meio e instrumento da linguagem, lugar no qual se organizam os significados sociais e culturais, lugar que explicita o discurso" (BENEDETTI; ROMÃO, 2007, s/p). Ao relacionar a postura que temos diante do corpo com as formas corporais sugeridas pelos mercados das dietas, Foxcroft é enfática: 
$\mathrm{O}$ atual excesso de autodepreciação, vergonha e infelicidade sem sentido de tentar e não conseguir ser a criatura ideal que nossa sociedade deseja precisa ser repensado [...] Todo mundo faz dieta de vez em quando, e a maioria de nós é especialista na autoilusão que, sejamos honestos, é necessária para iniciar um regime rápido, e talvez excessivo, de perda de peso [...] Devemos nos rebelar contra a futilidade da atual norma de beleza ocidental explorando e expondo a longa e suja história da modelagem do corpo e das dietas [...] Somos uma cultura em busca da dieta perfeita, e como prova disso há uma porção de pessoas infelizes e inseguras por aí (FOXCROFT, 2013, p. 18-19).

Uma das especificidades da mídia na eficácia de interpelação dos sujeitos é que ela parece "não deixar espaços para além de si para nenhum outro discurso, para nenhuma outra forma de sujeito, para nenhum corpo que lhe sirva como suporte" (PAYER, 2005, p. 19). Se estamos diante de uma nova prática discursiva, diz Payer (2005), se estamos diante de um outro real sócio-histórico, esse real também é impiedoso. No caso do mercado das dietas e boa forma, Foxcroft (2013, p. 11) é enfática: “gordura é 'ruim' e fazer dieta é a norma, mas poucas pessoas nas últimas décadas tiveram o que poderíamos denominar uma relação 'normal' com a comida, intocada pelo constante dilúvio de notícias sobre dietas".

Assim como o corpo não deve ser entendido apenas em sua estrutura física e biológica, tampouco a gravidez deve ser entendida apenas no sentido biológico do termo. Quando nos referimos à maternidade como algo biológico, trata-se apenas de uma questão semântica. As alterações corporais promovidas pela maternidade são de ordem orgânica. Daí o fato de atrelarmos, no presente texto, a gravidez ao seu sentido biológico. Contudo, não se trata de uma visão reducionista de um fenômeno tão complexo. A maternidade, além do seu lado corporal e físico, é um acontecimento atravessado por aspectos culturais, sociais, psicológicos e medicinais, entre outros.

Em Um amor conquistado: o mito do amor materno, a filósofa e historiadora francesa Elisabeth Badinter (1985) critica o fato de a maternidade e o amor materno serem reduzidos ao instinto, a uma tendência inata feminina. É um comportamento social, variável de acordo com a época e os costumes. Badinter assinala o devotamento e os 
sacrifícios que a mulher deve fazer pela criação dos filhos: "Amamentar, dar banho e comida, vigiar os primeiros passos, consolar, cuidar, tranquilizar à noite. São gestos de amor e de devotamento, mas são também sacrifícios que a mãe faz pelo filho" (BADINTER, 1985, p. 337).

A historiadora lembra ainda mais um suplício que a mulher enfrenta, principalmente nos dias atuais: "Sem dúvida o filho constitui uma dificuldade considerável para todas as mulheres que são obrigadas a trabalhar para viver" (BADINTER, 1985, p. 72). A mulher moderna se sente assoberbada com o acúmulo de funções na família e na vida profissional. Ela deve conciliar múltiplos afazeres, exercendo cada função com competência e um corpo sempre belo. Dentre as diferentes facetas da gravidez, biológicas ou culturais, neste trabalho pretendemos focar em um aspecto particular e relativamente novo: a homogeneização do formato do corpo da gestante promovido pelo discurso midiático das dietas e boa forma.

O corpo difundido pela mídia apresenta um aspecto perfeitamente magro, que não pode ceder ou ter seu formato alterado mesmo quando sofre a ação de um período como a gravidez. Os aspectos culturais da maternidade, em especial os obstáculos que a mulher litiga durante e após a gestação, parecem ser apagados, silenciados, pelo discurso da boa forma. É como se os sinais que o corpo apresenta como consequência de sua atividade reprodutiva (marcas de estrias, seios caídos e flácidos, o peso que se acumula após o parto) devessem ser repaginados.

Em um estudo recente (BOCCHI, 2019), a autora observou, no espaço virtual, movimentos contraditórios sobre a maternidade. $\mathrm{O}$ ato de ser mãe não suscita apenas sentimentos positivos. Há relatos "através do qual o sujeito partilha seus problemas e confessa suas dificuldades para com as demandas impostas por uma certa interpretação da maternidade em nossa sociedade" (BOCCHI, 2017, p. 131). Não bastassem todas as questões envolvendo a maternidade, o estresse e a ansiedade vivenciados por um grande número de mulheres após o parto, entre tantas outras adversidades envolvendo a gravidez, a mulher contemporânea depara-se com mais uma força coativa: a busca pela perfeição corporal durante e após o parto incentivada pelo discurso midiático da boa forma. Diante da amplitude do tema, a tensão entre o corpo real proporcionado pela gravidez e o 
protótipo de corpo promulgado pela mídia é ponto central das análises e reflexões que se seguem.

\title{
A geometrização do corpo e a diminuição da cintura
}

O abdômen feminino apresenta uma forte carga simbólica. É justamente ali que se encontra o útero, órgão atrelado à vida, à geração de uma nova vida. E, como um fenômeno biológico e natural, ao ficar grávida seu abdômen se expande durante os noves meses do desenvolvimento do feto.

\begin{abstract}
Aos vinte e poucos anos, tive dois bebês. Fiquei GRANDE. Quando ganhei dezenove quilos, dos quais apenas uns três correspondiam ao bebê, meu médico me passou um severo e paternal sermão sobre como eu estava engordando. Na verdade, ele me disse, com grande confiança, que eu "incharia como um balão" e que lutaria para perder peso se insistisse em amamentar (FOXCROFT, 2013, p.17).
\end{abstract}

O texto midiático da boa forma voltado para a mulher grávida opera como um dispositivo discursivo capaz de construir uma história do presente sobre a gravidez, articulando e emanando sentidos sobre a forma corporal da gestante. Gregolin (2007) aponta que a "mídia é o principal dispositivo discursivo por meio do qual é construída uma 'história do presente' [...] que formata a historicidade que nos atravessa e nos constitui" (GREGOLIN, 2007, p. 16). Se o discurso sobre a corporeidade feminina tem uma história e se constitui a partir de uma memória, as "partes" desse mesmo corpo também são faladas a partir de uma história e uma memória.

Diminuir a cintura não é algo novo na história da humanidade. Os primeiros espartilhos, peça usada para comprimir o abdômen e afinar a cintura, surgiram no século XVI e eram feitos com esteios rígidos de metal ou barbatanas de baleia. Se os espartilhos foram usados até o século XIX, no século XXI há inúmeras outras formas para afinar e moldar o abdômen da mulher. São recursos amplamente divulgados pelo discurso midiático da boa forma que, adotando a estratégia de geometrização do corpo, faz circular sentidos sobre a silhueta feminina. O corpo, que deveria ser visto como um todo, é compartimentado, retalhado, para ser trabalhado parte a parte, pedaço por pedaço, ou 
para usar uma linguagem empregada pela mídia do corpo-perfeito, músculo por músculo. Cada pedaço do corpo feminino é delineado de acordo com o padrão corporal vigente para ser mais feminino, sexualmente atraente e sempre jovial. Vejamos alguns exemplos:

\author{
Recorte 15: \\ Abdômen rasgado. É tendência, é sexy e é ousado \\ BARRIGA ZERO. Dicas de alimentação para mandar a pochete embora \\ Barriga dos sonhos \\ Conquiste sua barriga chapada \\ Cardápio termofuncional. Seca $6 \mathrm{~kg}$ e afina $4 \mathrm{~cm}$ na barriga em um mês \\ Zero barriga. Perca 5 centímetros de cintura com nosso cardápio \\ Barriga chapada. Perca $4 \mathrm{kG}$ em um mês com a dieta das castanhas \\ Barriga TOP. O treino da australiana responsável pelos antes e depois mais incríveis. \\ Tá bombando no Instagram! \\ BARRIGA SECA JÁ! Circuito Aero + Local \\ Cintura fina em um pulo! Estratégias e alimentos que derretem a gordura \\ abdominal
}

A formação discursiva do corpo-perfeito direcionada às mulheres é enfática ao cristalizar, através de discursos homogeneizantes, dizeres a respeito dessa parte do corpo feminino. A formação discursiva pode ser compreendida como o que, em um dado contexto sócio-histórico, define o que pode e deve ser dito, já que o sentido é afetado por meio da inscrição do discurso em uma determinada formação discursiva e não em outra(s), o que interfere na forma como o(s) sentido(s) são produzido(s) (BASTOS; GARCIA; SOUSA, 2014). Em outras palavras, a formação discursiva é constituída por um conjunto de dizeres que derivam de uma formação ideológica, formando discursos sobre determinado assunto. Dependendo da formação discursiva na qual o enunciado está inscrito, teremos outras produções de sentidos, por isso o sentido sempre pode ser outro (BASTOS; GARCIA; SOUSA, 2014).

$\mathrm{Na}$ formação discursiva da boa forma, o corpo feminino não pode envelhecer, sofrer a ação do tempo ou as imposições de um evento como a gravidez. Segundo Payer (2005), estamos diante de um flagrante da estreita relação entre a produção dos enunciados e a configuração da sociedade e de seus sujeitos. Na atualidade, definitivamente a mídia escolheu a cintura fina e a barriga isenta de gordura como um

\footnotetext{
${ }^{5}$ Todos os recortes foram selecionados do nosso corpus, detalhado no início do artigo.
} 
dos sinônimos de feminilidade e sensualidade. Não faltam adjetivos para enumerar as características e qualidades do formato abdominal aceito na atualidade para essa parte do corpo feminino. As denominações do formato do abdômen atuam discursivamente conferindo ao design da barriga efeitos de força, robustez, energia e vigor. Os "nomes próprios" promovem a constituição de sentidos dominantes ao indicarem a configuração e a dimensão exata da barriga (barriga chapada, dos sonhos, fina, negativa, rasgada, sarada, seca, top, trincada, zero, etc.). Por conseguinte, outros padrões são silenciados ou ridicularizados através de sentidos irônicos atribuídos à gordura abdominal (pochete, pneuzinho, gordurinhas ou dobrinhas).

As sequências discursivas acima reforçam uma de nossas teses sobre o texto midiático das dietas e boa forma: estamos diante de textos publicitários, que incitam e chamam a atenção do sujeito-leitor pelas artimanhas empregadas na construção dos enunciados. O verbo no imperativo se faz presente, convocando a mulher a afinar a cintura: "mande a pochete embora", "conquiste sua barriga chapada", "perca 5 centímetros de cintura". Não há, na formação discursiva do corpo-perfeito, espaço para outro tipo de corpo: portanto, não há lugar para outro formato de abdômen que não personifique a norma estabelecida pela mídia.

A iconografia das barrigas saradas legitima os enunciados através de repetidas imagens de abdomens perfeitos. São formas praticamente idênticas, de mulheres com a barriga perfeita, lisa, sem dobras, em sua maioria com os músculos do abdômen salientes, a tão desejada "barriga tanquinho". Um exemplo é a imagem divulgada nas redes sociais pela musa fitness Bella Falconi: 


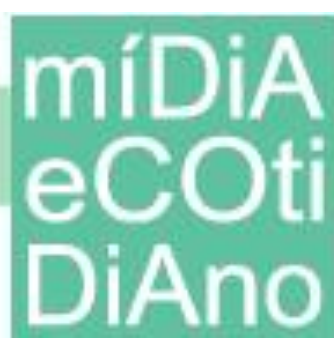

\section{PPGMC}
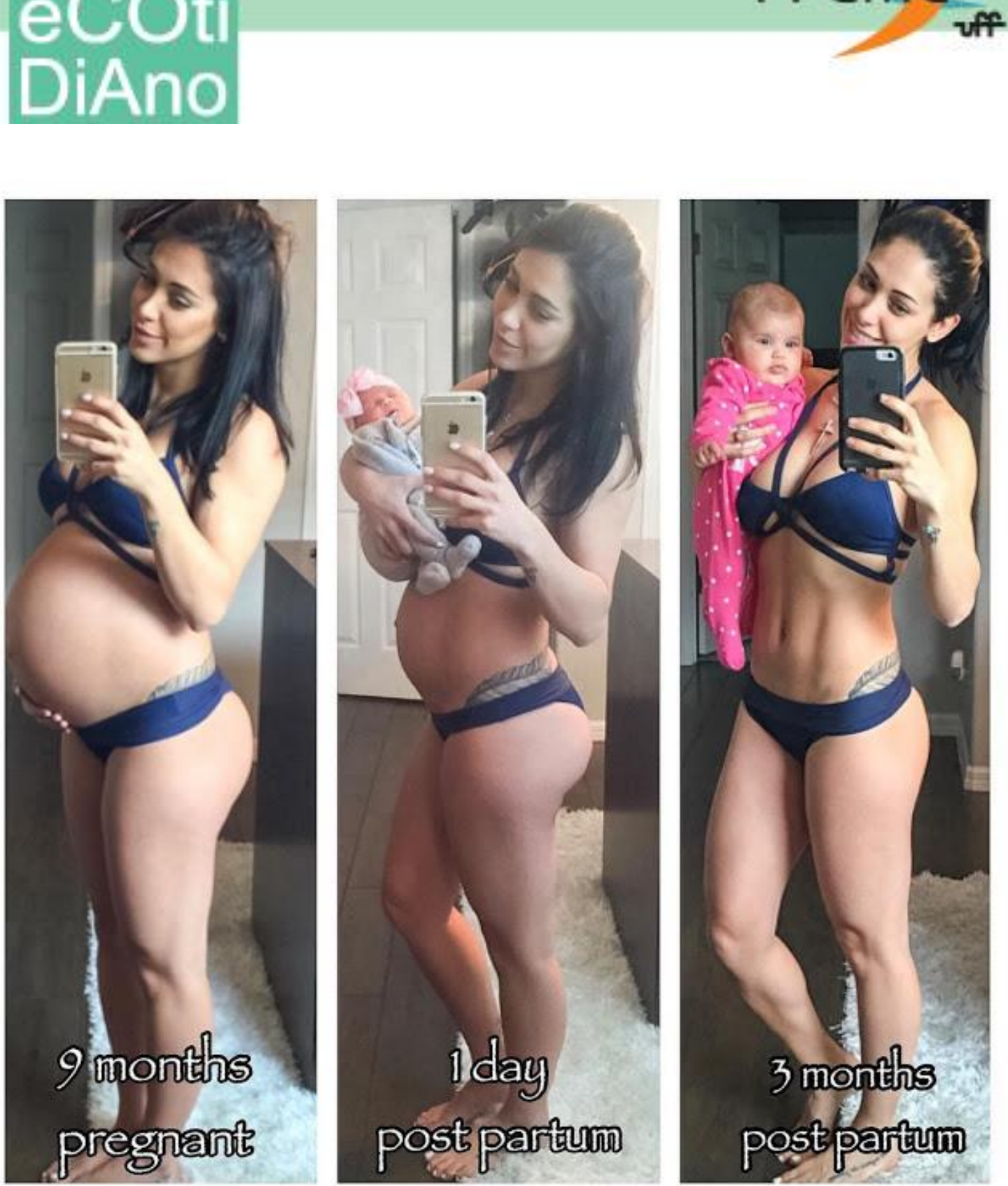

Figura 1 - A musa fitness Bella Falconi expõe o formato do corpo durante e após a gravidez. Fonte: Health ${ }^{6}$

O discurso da boa forma é construído e sedimentado sobre axiomas que indicam direções únicas, cristalizando aspectos culturais e homogêneos, sem, contudo, detalhar a origem de algumas sentenças. Um exemplo é o enunciado do recorte 1: "Abdômen rasgado. É tendência, é sexy e é ousado”. Os argumentos são poderosos e incidem sobre

\footnotetext{
${ }^{6}$ Recuperado em 5 de novembro de 2017, http://www.health.incommunseries.com/2015/11/bella-falconimostra-fotos-da-gravidez.html
} 
a mulher ao indicar e impor um determinado padrão corporal, atribuindo a essa configuração efeitos de feminilidade e sexualidade "sexy e ousado", além de configurar uma tendência. Para os profissionais de marketing, uma tendência é um direcionamento ou uma sequência de eventos com certa força e estabilidade que revelam, de certa forma, como será o futuro (KOTLER; KELLER, 2012). Ao tomar para si o poder de instituir o que é ou não tendência, a mídia geometriza o corpo e estipula qual arquétipo deve ser adotado para cada parte do corpo feminino. Como um dos atributos do discurso das dietas e boa forma é o imperativo da velocidade, as tendências mudam frequentemente. $\mathrm{O}$ discurso midiático das dietas trabalha discursivamente para promover, simultaneamente, efeitos de unidade dos sentidos (apontando tendências singulares), e efeitos de inovação e mudança (recriando e reformulando padrões estéticos e modelos imagéticos).

Outro aspecto relevante é que as empresas que constituem a chamada mídia são organizações com fins lucrativos. E funcionam em uma mecânica quase invisível, difícil de questionar, dirigindo-se "a nós com uma voz natural e transparente, sem qualquer referência à própria perspectiva tendenciosa" (BOTTON, 2015, p. 11). A imprensa, diz Mariani (2007), realiza uma espécie de catalogação do real, deixando-o simbolicamente disciplinado ao formular enunciados que estabilizam certos sentidos, sustentando-se no imaginário da transparência da linguagem e objetividade da notícia. "A criação dessa ilusão de 'unidade' do sentido é um recurso discursivo que fica evidente nos textos da mídia", diz Gregolin (2007, p. 16), ao enfatizar que aquilo que "os textos da mídia oferecem não é a realidade, mas uma construção que permite ao leitor produzir formas simbólicas de representação da sua relação com a realidade concreta".

Um exemplo desse cenário é a superficialidade com que a mídia (e o discurso das dietas e boa forma) aborda certos temas. Ao afirmar que a tendência é ostentar um abdômen "rasgado", a mídia sintetiza dizeres e valores sobre o ideal de beleza feminino sem, contudo, deixar claro quem é o responsável em definir o padrão adotado como referência estética. Esse exercício de apontar singularidades é exercido pela própria mídia. No discurso midiático das dietas, isso nos parece evidente: as revistas (que também são produtos midiáticos) apresentam os bens e serviços relatados em seus textos como objetos e procedimentos que ajudarão o sujeito-leitor a alcançar o corpo-perfeito. Tudo 
está à venda. O sujeito-leitor que compra a revista ou acessa o site é apresentado às últimas novidades para perder peso e delinear o corpo, através dos produtos relatados nos textos e destinados a essa finalidade. Do início ao fim, o discurso do texto midiático das dietas e boa forma parece ter como único objetivo fomentar um grande comércio para o sujeito-mulher tentar, a todo custo, alcançar o corpo-perfeito.

\section{A metáfora do elástico: forma-sujeito grávida perfeita}

Também chamado de sujeito do saber, sujeito universal ou sujeito histórico de uma determinada formação discursiva, a forma-sujeito é responsável pela ilusão de unidade do sujeito. Faz-se necessário, assim, examinar as propriedades discursivas da forma-sujeito como "sujeito do discurso":

A interpelação do sujeito indivíduo em sujeito de seu discurso se efetua pela identificação (do sujeito) com a formação discursiva que o domina (isto é, na qual ele é constituído como sujeito): essa identificação, fundadora da unidade (imaginária) do sujeito, apoia-se no fato de que os elementos do interdiscurso (sob sua dupla forma, descrita mais acima, enquanto "pré-construído" e "processo de sustentação") que constituem, no discurso do sujeito, os traços daquilo que o determina, são re-inscritos no discurso do próprio sujeito (PÊCHEUX, 2009, p. 150 - grifos nossos).

A forma-sujeito, que aqui denominamos grávida perfeita, é um fenômeno midiático que pode ser notado em práticas discursivas relativamente recentes. Assim como em toda atividade lucrativa, o mercado das dietas está em constante expansão para angariar outras formas de sujeito, investindo em todas as frentes possíveis que possam gerar lucro na exploração de uma imagem idealizada do corpo feminino.

Antes de avançarmos, precisamos fazer uma ressalva em relação ao nebuloso conceito de "mercado". O mercado, explica Baitello (2005), é um entre tantos textos culturais elaborados pela inventividade humana: é uma relação comunicativa, uma criação social, uma rede complexa de relações comunicativas, econômicas, sociais e políticas. Por sua vez, ao operar discursivamente por intermédio da mídia, o mercado produz efeitos de sentidos ao exigir dos sujeitos certas condições de existência. Na relação 
entre o corpo real e o corpo difundido pela mídia, Naomi Wolf aponta a necessidade econômica dos mercados como matriz propulsora de uma geometria corporal feminina, o que ela batiza de "mentira vital": "Embora ansiedades pessoais e inconscientes possam representar uma força poderosa na criação de uma mentira vital, a necessidade econômica praticamente garante sua existência" (WOLF, 2018, p. 36).

Um comportamento que seja essencial por motivos econômicos, diz o economista Jonh Kenneth Galbraith, "é transformado em virtude social” (apud Wolf, 2018, p. 37). Mídia e mercado atuam em uma via de mão dupla: a mídia funciona legitimando as ações do mercado, atuando na constituição e naturalização de sentidos vistos como necessários ao processo de organização e atuação das corporações, que usam os recursos midiáticos para legitimar sentidos e garantir as condições para a realização de suas ações. Em síntese, para promover e expandir o consumo.

O jornalista e escritor italiano Roberto Saviano (2014) traça um panorama mordaz dessa lógica capitalista. Ele equipara o momento atual do capitalismo a um elástico esticado à extensão máxima, próximo do ponto de ruptura. "Todo nicho de mercado foi conquistado, toda necessidade, satisfeita" (SAVIANO, 2014, p. 79). Todos os bens inclusive os produzidos pelo mercado da boa forma - são obrigados a se submeter à regra do elástico. Um exemplo de como o mercado tenta esticar o elástico para expandir sua atuação é a formação discursiva sobre o corpo-novo durante e após a gravidez. Caso a mulher engravide, deve empenhar-se em retomar a aparência anterior à gravidez (ou até mais magra, bela e jovem). Vejamos alguns exemplos que circulam em nosso corpus:

\footnotetext{
Recorte 2:

Luciana Gimenez. 45 anos, dois filhos, barriga desenhada e pele de bebê com ioga e técnicas high tech

Ana Hickman: corpão depois da gravidez

Juliana Paes. 35 anos, 2 filhos, conta como perdeu os 16 quilos da gravidez

Angélica. 41 anos, 3 filhos, revela sua receita de suchá detox

Fernanda Motta. Linda e sexy aos 34 anos, mãezona e louca por pilates e coxinha

Circuito barrigão. Já se foi o tempo em que a grávida devia substituir o exercício

habitual pela hidroginástica

Força para dar colinho
} 
O discurso do corpo-perfeito na pós-gravidez inscreve efeitos de sentidos tidos como naturais também no recorte abaixo:

\section{Recorte 3:}

Samba na cara da sociedade com três filhos e esse corpinho! Ai, ai, ai...

Os comentários dos sujeitos-leitores são em sua maioria encomiastas -derramamse em elogios para as imagens do corpo-perfeito das celebridades preferidas. Não há espaço para observações infames. O "corpinho" a que se refere o leitor evoca sentidos de jovialidade e magreza. O "samba na cara" remete a efeitos de sentidos de "zombar" dos sujeitos-normais, o conjunto da sociedade com estilos de vida que dificultam a obtenção dos patamares de primazia exigidos pela ideologia das dietas e do corpo-perfeito (ou seja, a maioria esmagadora dos sujeitos da nossa sociedade).

Há também o endosso das celebridades, que faz funcionar no discurso o efeito de superação e realização. As celebridades, enfatiza Botton (2015), são mais velozes, mais fortes, mais criativas, mais ricas, mais belas, mais sensuais, mais jovens do que o cidadão comum. Suas realizações nos estimulam e nos seduzem, já que "o desejo de ser famoso é uma tentativa de fazer com que nossa dignidade seja respeitada em um mundo em que quase certamente não o será” (BOTTON, 2015, p.154). E a fama midiática está atrelada ao corpo. Nesse sentido, a fama se revela no/pelo corpo, uma vez que "os sujeitos textualizam seu corpo pela maneira mesma como estão nele significados, e se deslocam na sociedade e na história: corpos segregados, corpos legítimos, corpos tatuados" (ORLANDI, 2012, p. 19), corpos-perfeitos, corpos-magros, corpos-projetados, corpos(re)fabricados. Nesse espaço discursivo/midiático, se o sujeito é famoso, sua fama se faz através de seu corpo. Não são apenas suas ideias ou ideais que estamparão seus nomes no universo midiático, mas essencialmente seus rostos e corpos.

Pensando nos recortes acima, não basta ser mãe, é impreterível ter a barriga desenhada, a pele tão lisa e brilhante quanto a de um bebê, ser linda e sexy, louca por pilates (exercícios) e, além disso, se dar ao luxo de ingerir frituras sem engordar. Esse discurso contraditório provoca efeitos ambíguos ao sugerir que a mulher pode ingerir alimentos altamente calóricos e, ao mesmo tempo, emagrecer. A contradição parece agir 
como um pêndulo, situando o sujeito em uma forma de funcionar/existir e simultaneamente deslocando-o para diferentes condições de existência. $\mathrm{O}$ agenciamento das subjetividades não ocorre de forma completa, mas em "um permanente entrelaçamento móvel entre as forças de territorialização e as de desterritorialização, ambas agindo e provocando contradições" (GREGOLIN, 2017, pp. 23-24),

O corpo na/da atualidade deixou de ser a identidade de si para se tornar, na visão de Le Breton (2003), um kit, uma soma de partes destacáveis disponíveis a todo tipo de modificação proporcionada pela indústria do design corporal. Se essa indústria é composta pela soma de diversas atividades como dietas, exercícios e cirurgias estéticas, as publicações impressas e virtuais voltadas para boa forma dão publicidade e legitimidade a essas alterações corporais.

A ideologia da magreza e a forma sujeito grávida-perfeita é enfática: a mulher deve ter uma barriga "tanquinho, sequinha, desenhada, definida", mesmo após a gravidez. Ela deve manter-se magra em qualquer situação ou idade; nada pode atrapalhar o formato do seu corpo. Se ganhar uns quilos a mais por conta da gravidez, deve recrudescer na tentativa de se livrar dos efeitos indesejados e renovar a aparência.

\section{Recorte 4:}

Gerar uma vida é tão incrível que a gente acaba relevando os efeitos colaterais. No fim das contas, me sinto mais bonita do que antes

O que deveria ser natural passa a ser "efeito colateral" do ato de engravidar. Esse discurso também faz ressoar ecos de uma nova mulher, mais bonita e feliz:

\section{Recorte 5:}

"A gravidez está passando muito rápido! Torço para que a Vicky venha na hora certa e com muita saúde. E, quando isso acontecer, também nascerá uma nova Bella", diz a musa fitness, que durante toda a gestação não parou de se exercitar.

Poderíamos fazer um gesto de leitura de que a "nova Bella" será uma nova mulher frente ao desafio de cuidar de seu filho recém-nascido. Mas, como os sentidos deslizam por efeito metafórico, ao abarcar os enunciados "mais bonita do que antes", "durante toda a gestação não parou de se exercitar", o surgimento de uma nova mulher (a nova Bella) é 


\section{míDiA

um discurso que também remete a sentidos de um corpo novo, melhor e aprimorado em sua aparência.

Em seus discursos, Bella Falconi (recorte 4) usa a expressão "efeitos colaterais" para denominar as transformações corporais inerentes à gravidez. A determinação na busca do corpo-perfeito está atrelada ao exibir, aparentar, ser visto (seja na vida real ou virtual). O corpo-perfeito deve ser mostrado. Mas a busca da perfeição se choca com o corpo-vivo e suas limitações. O corpo real não é definitivo. Ele muda de formato nas várias fases da vida, como ocorre na gestação. A gravidez enseja profundas modificações no corpo feminino. Mas, para uma "blogueira fitness", as transformações são vistas como deformações. O corpo-perfeito, irretocável, não pode engordar. Suas formas não podem ser alteradas. $\mathrm{O}$ que deveria ser uma experiência natural passa a ser encarada como algo ilógico (colateral) e até surpreendente, principalmente para uma mulher cujas atividades estão atreladas à imagem do seu corpo-perfeito (e a sua constante exibição).

Como vimos na figura 1 , o corpo alterado durante o período gestacional é rapidamente atualizado, reconfigurado e retrabalhado para adquirir ou reconquistar os contornos anteriores (uma silhueta magra, bem definida, musculosa e sem gorduras ou dobras aparentes). A forma sujeito grávida-perfeita permite ao mercado das dietas possibilidades lucrativas com a edição de livros voltados para as práticas de exercícios durante a gravidez, roupas específicas para atividade física durante a gestação, cosméticos e alimentos, além de profissionais como o "personal gestante".

\section{Efeitos de completude: repetidas histórias de perfeição}

O discurso midiático da boa forma, atrelado à formação discursiva do corpoperfeito, é um fenômeno dinâmico, vivo, complexo, composto por múltiplos cenários que se desdobram em milhares de facetas, possibilitando uma infinidade de leituras possíveis. Podemos analisar o que dá sustentação a essas relações de sentido, um discurso organizado e organizador cuja força se dá pela repetição de imagens tecnicamente produzidas, mas também de enunciados, construções linguísticas de cunho publicitário/jornalístico. Analisar um discurso "significa tentar compreender a maneira como as verdades são produzidas e enunciadas" (GREGOLIN, 2007, p. 15). Para 
exemplificar esse processo discursivo que faz da repetição uma arma na construção de axiomas, de juízos que parecem ser incontestáveis, selecionamos quatro publicações de nosso corpus.

Nosso intuito é mostrar como o mesmo discurso (e sua materialidade significante, composta por enunciados e imagens) se repete e faz ecoar efeitos de sentidos que apontam, se não para um único caminho, para um conjunto de artifícios simbólicos e imagéticos presentes nas formações ideológicas do projeto de corpo perfeito das mulheres que tiveram filhos e conseguiram formas corporais invejáveis após a gravidez. A narrativa midiática explora vários aspectos, reforçando os sentidos sobre o corpo-perfeito das celebridades que estampam a capa das quatro publicações escolhidas (que denominaremos nos recortes a seguir de Revista 1, Revista 2, Revista 3 e Revista 4).

\footnotetext{
Recorte 6:

Revista 1: Letícia Birkheuer. Loira, linda e magra!

Revista 2: Dona de uma barriga chapada, pernas torneadas e uma silhueta maravilhosa. Esta é a Angélica.

Revista 3: Nesse corpão, agora habitam a Ana mulher, a profissional e a mãe.

Revista 4: Dois filhos e um corpão, Juliana Paes é mesmo um fenômeno! (grifos nossos)
}

Após desfilar elogios aos corpos esculturais, os enunciados convocam o sujeitoleitor a conhecer a rotina e a trajetória das celebridades na conquista do corpo-perfeito após a gravidez. Os efeitos resultantes desses discursos projetam as celebridades ao posto de modelos (não apenas de beleza corporal), mas de vida, perseverança, atitude e dinamismo. Referências a serem copiadas pela mulher comum, seja pela inveja ou admiração, além de um processo de identificação suscitado pelo discurso e materializado na linguagem.

\footnotetext{
Recorte 7:

Revista 1: É isso o que a maioria das mulheres deseja. E a atriz Letícia Birkheuer tem esse perfil. Ficou com invejinha?

Revista 2: A cada ano que passa ela fica ainda mais bonita e segura de si. Afinal, são muitos aprendizados que a apresentadora faz questão de seguir para cuidar de seu corpo e bem-estar. Aprenda com ela!
} 
Revista 3: A vida de Ana Hickman daria uma bela história de amor. Ela é movida pela paixão - para alcançar o sucesso profissional, ser mãe ou mesmo reconquistar o corpão de antes da gravidez. A intensidade dela é contagiante! Quer ver? [...] Como chegou lá? Vem descobrir.

Revista 4: Mas, como qualquer mulher, Juliana precisou dar duro para recuperar a silhueta depois das gestações. (grifos nossos)

"É isso o que a maioria das mulheres deseja", impõe um dos enunciados. "Isso" e não "aquilo": a pluralidade não faz parte desse enredo. O sujeito-mulher não pode desejar outra coisa senão aquilo que, segundo o discurso da mídia, a maioria das mulheres deseja, mas que no fundo sabemos que é imposto pela própria mídia. Os sentidos que circulam na mídia sobre o formato ideal de beleza do corpo feminino estão além do reflexo da vontade do sujeito atual. Ao incitar a mulher moderna a emagrecer o mais rápido possível após o parto, as publicações estariam apenas refletindo a vontade do sujeito? Defendemos que não. $\mathrm{O}$ aparato midiático é dotado de incrível capacidade técnica de manipular o imaginário simbólico para suscitar vontades e desejos voltados exclusivamente para o consumo.

A faculdade da mídia em intervir nas escolhas do sujeito não pode ser vista como algo inofensivo. É impossível negar a força da mídia enquanto matriz criadora de valores simbólicos, estéticos e sociais. Sustentar que a mídia capte a vontade do sujeito e entregue apenas aquilo que ele já gostaria de consumir é, de certo modo, ignorar a capacidade das organizações de mídia em manipular o simbólico, construir identidades e influenciar subjetividades, suscitar desejos e atitudes de e para o consumo. Em nossa época, diz Gregolin (2007, p. 24), “a mídia é uma fonte poderosa e inesgotável de produção e reprodução de subjetividades, evidenciando sua sofisticada inserção na rede de discursos que modelam a história do presente".

Benjamin Barber expõe sua indignação quando ouve os ativistas dos mercados defenderem a pretensa autonomia dos consumidores: "Como se os gostos dos consumidores fossem criados partir do nada! Como se os desejos e as necessidades sobre as quais prosperam os mercados não fossem, eles mesmos, engendrados e moldados por estes mesmos mercados" (BARBER, 2003, p. 50). O discurso midiático do mercado da 


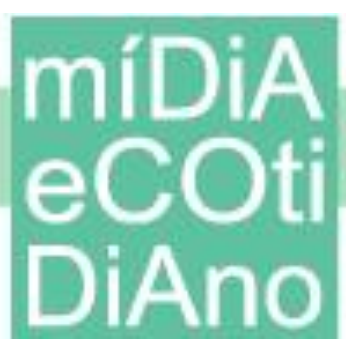

boa forma vai muito além do que simplesmente atender as necessidades, anseios e desejos da mulher coetânea.

As revistas de boa forma e vida saudável atuam no contexto midiático legitimando um ideário sobre o corpo da grávida-perfeita e como fazer para alcançá-lo. Quando o enunciado reforça que "a maioria das mulheres deseja" um corpo escultural como o de uma celebridade, há um processo imaginário de inserção do sujeito-leitor na mesma formação discursiva. Se a maioria das mulheres deseja algo, a leitora também é inserida nesse grupo e arrastada a desejar as mesmas coisas. Outro sistema imaginário de identificação ocorre quando os enunciados ressaltam que uma celebridade, "como qualquer mulher", conseguiu fazer isso ou aquilo. Em um jogo discursivo, os efeitos desse discurso promovem um nivelamento tanto da leitora comum quanto da celebridade ao mesmo patamar, cessando as diferenças econômicas, sociais, de disponibilidade de tempo e dinheiro, entre tantas outras diferenças, que separam de forma abismal as celebridades da mulher comum. O caldeirão de sentidos que exalam do texto midiático das dietas e boa forma ao direcionar agora seus tentáculos para a gravidez busca mais uma vez fundar uma discursividade que inscreve/escreve formulações sobre a mulher, em especial, a mulher grávida.

O discurso é formulado de modo a direcioná-lo aos medos e anseios da mulher na atualidade, como o medo de engordar e a obsessão por retomar o mais rápido à melhor forma física possível após a gravidez; o que, em muitos casos, é praticamente impossível. Deste modo, o discurso inscreve a naturalização do sentido de que as parturientes famosas voltaram a ter um corpo magro e definido logo após o nascimento dos seus filhos.

\section{Recorte 8:}

Revista 1: E por falar no filho, a estrela conta que engordou $22 \mathrm{~kg}$ na gestação [...] "Seis meses depois já estava no meu peso", revela a estrela.

Revista 2: [...] aos 41 anos, desfila com seus 56 quilos muito bem distribuídos nos $1,64 \mathrm{~m}$ de altura, mesmo após a gestação de seus três filhos.

Revista 3: Ela lembra que, depois de ter ganhado 30 quilos na gravidez, o quadril foi o primeiro a voltar à medida anterior [...]. A batalha foi grande, mas em sete meses ela já pesava 69 quilos de novo.

Revista 4: "Engordei 16 quilos em cada gravidez e tive de correr atrás" [...] Aos 35 anos, Juliana levou nove meses para voltar à forma e diz que deseja eliminar 2 quilinhos. (grifos nossos) 
A mulher é interpelada a realizar incessantes investimentos e movimentos de superação para formatar seu corpo aos paradigmas estabelecidos pelo corpo-perfeito. $\mathrm{O}$ recorte acima reforça os sentidos que permeiam o discurso das dietas e recaem sobre a mulher nos dias atuais: quem engorda precisa emagrecer. Mesmo após a gestação de um ou mais filhos: engordou? Emagreça. As celebridades conseguem, e você também! Basta conhecer os "segredos" ou "passos" de cada uma e colocá-los em prática:

\footnotetext{
Recorte 9:

Revista 1: E aí, dá para seguir os passos da bonita, né? Ela não faz nada além do que você possa fazer também. Que tal começar ainda hoje?

Revista 2: O segredo? Na verdade, são vários! Mas eles se resumem em uma combinação de alimentação supersaudável e atividade física.

Revista 3: A batalha foi grande, mas em sete meses ela já pesava 69 quilos de novo e, em um ano, vestia a mesma calça jeans.

Revista 10: E, apesar de dizer que come um pouco de tudo, como fazem as francesas, esta mulher alegre e cheia de energia tem muitos segredos. A atriz prioriza um cardápio sem lactose e sem glúten e investe nos alimentos funcionais e nos sucos detox.
}

Os passos para almejar o corpo perfeito se resumem a fazer isso ou aquilo, pois tudo é acessível e descomplicado. Os enunciados fazem ressoar efeitos de sentidos de disponibilidade e acessibilidade: não há nada que as celebridades fazem que o sujeitocomum não possa fazer, ou não esteja disponível e ao alcance de todos, quando sabemos que as celebridades possuem recursos financeiros suficientes para subsidiar os tratamentos de alto custo vedados à grande maioria das mulheres.

As narrativas anteriores são seguidas por imagens que praticamente se repetem. Produzidas, maquiadas, com roupas de banho (biquíni, maiô) ou roupa de ginástica, as imagens dos corpos exuberantes das personagens deixam a barriga à mostra, sempre em poses sensuais. Os cabelos estão perfeitamente cuidados, e a pele é lisa e exibe um brilho e uma textura homogêneos, de uma alvura quase absoluta e um aspecto prodigioso, divino, cujas qualidades excedem o mais perfeito espécime humana. Os enunciados fazem circular efeitos de sentidos ancorados em uma permanente contradição: ao mesmo tempo que são seres que habitam um outro universo, o das celebridades, com recursos financeiros suficientes para arcarem com os altos custos dos procedimentos estéticos de 


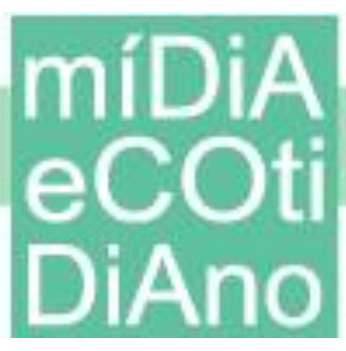

lapidação da aparência corporal, a narrativa sugere que tudo está disponível e ao alcance de todos.

\section{Considerações finais}

Para o texto midiático das dietas e boa forma, a mulher que passa pelo processo gestacional deve ostentar um corpo-perfeito, magro, seja através de dietas milagrosas, exercícios ou outras práticas para perder gordura. Em um movimento interminável, sujeito e discurso realizam-se juntos, em novidades e modismos que imprimem ao corpo do sujeito-mulher um "estar no mundo", a aceitação programada e possível pela via da aparência física.

E a mídia trabalha repetidamente os discursos das dietas e boa forma convocando e instigando o sujeito-leitor a conhecer e a compartilhar histórias de completude, perfeição, bem-estar psíquico, material (econômico) e físico (corpo-perfeito) das celebridades midiáticas. Para isso, o sujeito-leitor é incitado a desejar um corpo perfeito, já que uma vida perfeita se materializa em um corpo igualmente perfeito. "Ficou com invejinha?", questiona um dos enunciados. "Aprenda com ela", ordena o texto de outra publicação. A completude parece se materializar nas medidas corporais, postadas ao lado das imagens perfeitas; ao fato de que elas não envelhecem com o passar dos anos, mas estão cada dia mais bonitas; e também pelo fato de alcançarem o sucesso profissional ao mesmo tempo em que se comportam como esposas e mães maravilhosas, são autoconfiantes, seguras de si, e reconquistaram o "corpão" que já tinham mesmo após o processo gestacional.

Nesse enredo discursivo, não há espaço para falhas, dúvidas, medos, anseios, separações, quebras (físicas ou psicológicas), muito menos para olheiras, rugas, manchas, estrias, gorduras salientes, barrigas grandes, seios caídos, celulite. O corpo-perfeito proposto pela mídia, metafísico, não aceita erros, não está sujeito às falhas que corrompem o imaginário de uma beleza suprema. Também não aceita a ineficiência daqueles que sucumbem as contingências da vida cotidiana e deixam manifestar, no seu próprio corpo, o solecismo e a imperfeição. 
Os enunciados fornecem de maneira veemente os segredos de cada celebridade para atingir a plena realização e satisfação em todos os aspectos da vida, em especial com o design corporal. As publicações das dietas e boa forma atuam como uma Caixa de Pandora: diante dos males do mundo e da banalidade da vida cotidiana, a esperança está na possibilidade de espelhar-se naqueles que alcançaram sucesso, fama, poder, completude. A esperança midiática do corpo-perfeito não é possível de ser apanhada; como não existe, nunca será libertada. Os efeitos de sentidos dos enunciados reverberam um caminho a ser seguido pelo sujeito comum, com base nas histórias de superação das celebridades, para alcançar o corpo-perfeito oriundo de uma vida mágica, de saúde e bemestar.

São efeitos de sentidos que acabam por ditar como a mulher contemporânea deve se comportar em relação ao seu corpo mesmo diante das transformações biológicas promovidas pela gravidez, ou seja, como ela deve se significar através de um corpo que se textualiza, significa, tem sua carne retrabalhada e reconfigurada por agentes midiáticos.

\section{Referências}

BADINTER, E. Um Amor conquistado: o mito do amor materno. Rio de Janeiro: Nova Fronteira, 1985.

BAITELLO JR., N. A era da Iconofagia: ensaios de comunicação e cultura. São Paulo: Hacker Editores, 2005.

BARBER, B. Cultura McWorld. In: MORAES, D. (Org.). Por uma outra comunicação: mídia, mundialização cultural e poder. Rio de Janeiro: Record, 2003. P. 41-56.

BASTOS, G. G.; GARCIA, D. A.; SOUSA, L. M. A. S. O discurso na rede eletrônica e o Google: o movimento LGBT em destaque. Revista RUA, Campinas, v. 20, n. 2, p. 33-50, 2014.

BENEDETTI, C. R.; ROMÃO, Lucília S. . O CORPO COMO DISCURSO: um contraponto à noção de Informação. In: XXX Encontro Nacional de Estudantes de Biblioteconomia, Documentação, Ciência da Informação e Gestão da Informação, 2007, São Carlos. Anais do XXX ENEBD, 2007.

BOCCHI, A. F. de A. Efeitos de maternidade no post: movimentos de sentido entre estabilização e resistência. Diálogo das Letras, Pau dos Ferros, v. 06, n. 02, p. 119-138, jul./dez. 2017.

BOTTON, A. Notícias: manual do usuário. Rio de Janeiro: Intrínseca, 2015.

FOXCROFT, L. A tirania das dietas: dois mil anos de luta contra o peso. São Paulo: Três Estrelas, 2013. 
GREGOLIN, M. R. Análise do discurso e mídia: a (re)produção de identidades. Revista Comunicação Mídia e Consumo, São Paulo, v. 4, n. 11, p. 11-25. 2007.

KOTLER, P.; KELLER, K. L.; Administração de Marketing. 14 ed. São Paulo: Pearson Education do Brasil, 2012.

LE BRETON, D. Adeus ao corpo: antropologia e sociedade. Campinas: Papirus, 2003.

MARIANI, B. Imprensa, produção de sentidos e ética. In: RIBEIRO, A. P. G.; FERREIRA, L. M. A. (orgs.). Mídia e memória. A produção de sentidos nos meios de comunicação. Rio de Janeiro: Mauad, 2007, P. 199-218.

ORLANDI, E. P. Processos de significação, corpo e sujeito. In: AZEVEDO, A. F. (org.). Sujeito, corpo, sentidos. Curitiba: Appris, 2012, P. 13-30.

PAYER, M. O. Linguagem e sociedade contemporânea - sujeito, mídia, mercado. Revista RUA, Campinas, v. 11, n. 1, p. 09-25, 2005.

PÊCHEUX, M. Semântica e Discurso: uma crítica à afirmação do óbvio. Campinas: Editora da Unicamp, 2009.

SAVIANO, R. Zero Zero Zero. São Paulo: Companhia das Letras, 2014.

WOLF, N. O mito da beleza: como as imagens de beleza são usadas contra as mulheres. Rio de Janeiro: Rosa dos Tempos, 2009. 